This document is confidential and is proprietary to the American Chemical Society and its authors. Do not copy or disclose without written permission. If you have received this item in error, notify the sender and delete all copies.

\title{
Charge Transfer Pathways in Three Isomers of Naphthalene-Bridged Organic Mixed Valence Compounds
}

\begin{tabular}{|r|l|}
\hline Journal: & The Journal of Organic Chemistry \\
\hline Manuscript ID & jo-2015-02427h.R1 \\
\hline Manuscript Type: & Article \\
\hline Date Submitted by the Author: & 11 -Dec-2015 \\
\hline & $\begin{array}{l}\text { Schmidt, Hauke; University of Basel, Department of Chemistry } \\
\text { Neuburger, Mariana; University of Basel, Chemistry Department } \\
\text { Palivan, Cornelia; University of Basel, Chemistry Department } \\
\text { Meuwly, Markus; University, Chemistry } \\
\text { Wenger, Oliver; University of Basel, Department of Chemistry }\end{array}$ \\
\hline
\end{tabular}

SCHOLARONEm

Manuscripts 


\title{
Charge Transfer Pathways in Three Isomers of
}

\section{Naphthalene-Bridged Organic Mixed Valence}

\author{
Compounds
}

Hauke C. Schmidt, Mariana Spulber, Markus Neuburger, Cornelia G. Palivan, Markus Meuwly, * and

Oliver S. Wenger*

Department of Chemistry, University of Basel, St. Johanns-Ring 19, Spitalstrasse 51, and Klingelbergstrasse 80, CH-4056 Basel, Switzerland

m.meuwly@unibas.ch; oliver.wenger@unibas.ch
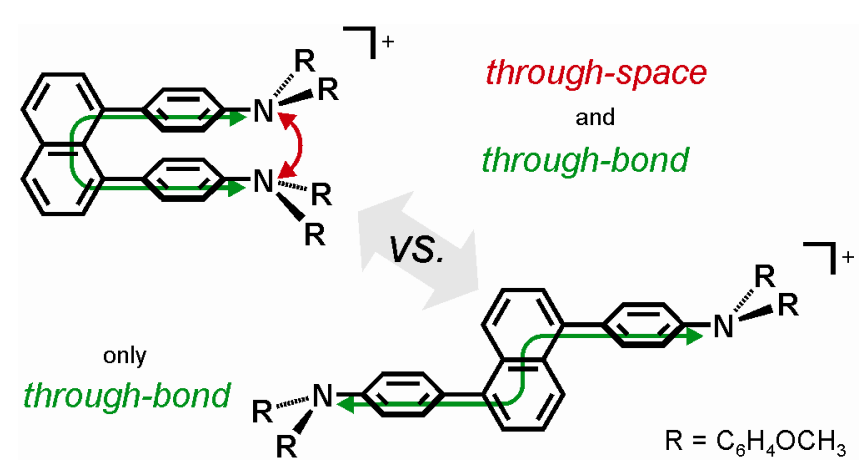


\begin{abstract}
Naphthalene was substituted at different positions with two identical triarylamine moieties to result in species which are mixed-valence compounds in their one-electron oxidized forms. They were investigated by cyclic voltammetry, optical absorption, EPR spectroscopy, X-ray crystallography, and DFT calculations. When the two redox-active triarylamine moieties are connected to the 2- and 6positions of the naphthalene bridge, their electronic communication is significantly stronger than when they are linked to the 1- and 5-positions, and this can be understood on the basis of a simple throughbond charge transfer pathway model. However, this model fails to explain why electronic communication between triarylamine moieties in the 1,5- and 1,8-isomers is similarly strong, indicating that through-space charge transfer pathways play an important role in the latter. In particular, charge transfer in the 1,8 -isomer is likely to occur between the triarylamino $\mathrm{C}$-atoms in $\alpha$-position to the naphthalene linker because the respective atoms are only about $3 \AA$ apart from each other, and because they carry significant spin density in the one-electron oxidized forms of triarylamines. This particular through-space charge transfer pathway might be generally important in molecular structures based on the 1,8-disubstituted naphthalene pillaring motif.
\end{abstract}




\section{INTRODUCTION}

Charge transfer across phenylene units has received much attention in the past, both in studies of photoinduced electron transfer in donor-bridge-acceptor compounds and in investigations of charge transfer between two electrodes. ${ }^{1}$ Naphthalene-based structures as molecular bridges for long-range charge transfer are much less well explored, ${ }^{2}$ but recently developed new synthetic methods make such structures much more amenable. ${ }^{3}$ Depending on the naphthalene substitution pattern significant differences in charge transfer properties have been reported, ${ }^{4}$ in analogy to what was found when comparing ortho-, meta- and para-substituted phenylenes. ${ }^{5}$ Several recent studies have attempted to identify orbital rules for charge transfer and charge transport in naphthalenes and related aromatic molecules. ${ }^{6}$ We were particularly interested in charge transfer between redox partners attached to the 1and 8-positions of a naphthalene bridge because this particular substitution pattern leads to molecular structures in which through-space charge transfer can potentially occur. ${ }^{7}$ One notable study has made use of 1,8-naphthyl pillars to enforce $\pi$-stacking of individual phenylene units, and photoinduced charge transfer in the resulting system presumably occurred to a significant extent via a through-space pathway. ${ }^{8}$ However, to our knowledge a direct comparison of charge transfer across 1,8-naphthylene bridges and isomers with other substitution patterns has not been performed until now. We consider this interesting because such a comparative study can provide direct insight into the relative importance of through-bond versus through-space charge transfer pathways.

Investigation of mixed-valence compounds is attractive for exploring charge transfer because it relies on the synthesis of symmetrical molecules rather than on unsymmetrical donor-bridge-acceptor compounds. Moreover, mixed valence studies can be performed with comparatively simple experimental techniques. Organic mixed valence species are particularly well-suited because they often exhibit intervalence charge transfer (IVCT) bands which are readily detectable. ${ }^{9}$ We chose triarylamines as redox-active units and connected them to each other via 1,8-, 1,5- and 2,6-naphthylene bridging motifs (left 
three structures in Scheme 1). Two naphthalenes with only one attached triarylamino-group were used as reference compounds (right two structures in Scheme 1).

Scheme 1. Molecular structures of the investigated compounds.

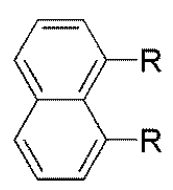

$(\mathrm{N}-1,8)$

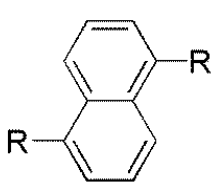

$(\mathrm{N}-1,5)$

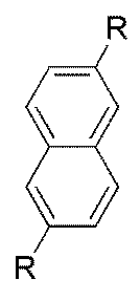

$(\mathrm{N}-2,6)$

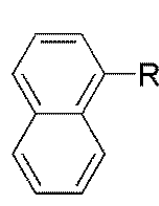

(N-1)

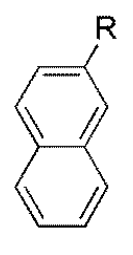

(N-2)

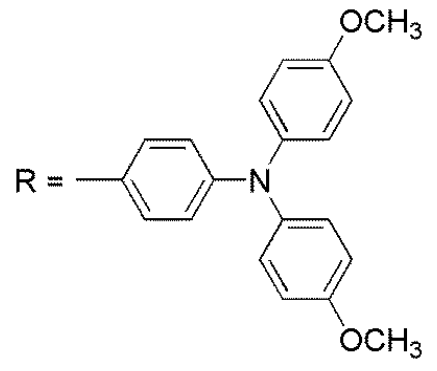

\section{RESULTS AND DISCUSSION}

Synthesis and crystallographic studies. All compounds from Scheme 1 are accessible in a straightforward manner using Pd-catalyzed cross coupling reactions between iodo- or bromonaphthalenes ${ }^{2 \mathrm{~b}}$ and a boronic ester of the triarylamine unit. ${ }^{10}$ The final products were characterized by ${ }^{1} \mathrm{H}$ and ${ }^{13} \mathrm{C}$ NMR spectroscopy, high-resolution mass spectrometry, and elemental analysis (see Supporting Information).

Single crystals of compound $(\mathbf{N}-\mathbf{1 , 8})$ were obtained by diffusion of pentane into a dichloromethane solution. The result of an X-ray diffraction analysis is shown in Figure 1; full crystallographic details are in the Supporting Information. The phenyl rings which are directly attached to the naphthyl unit are twisted away from the naphthalene plane by $53.6^{\circ}$. The respective two phenyl planes are not coplanar but bend away from each other with an angle of $26.6^{\circ}$, similar to what has been observed in related Xray structures. ${ }^{11}$ This results in distances of 2.971(2) $\AA$ between the triarylamine carbon atoms in $\alpha$ position to the naphthyl unit and a distance of 5.082(2) $\AA$ between nitrogen atoms. The respective distances are measured between $\mathrm{C}$ or $\mathrm{N}$ atoms and symmetry related counterparts produced by the (1-x, 
1-y, z) symmetry operator. The three aryl-groups around each $\mathrm{N}$ center are oriented in propeller-like fashion, as is commonly the case in triarylamines. ${ }^{12}$

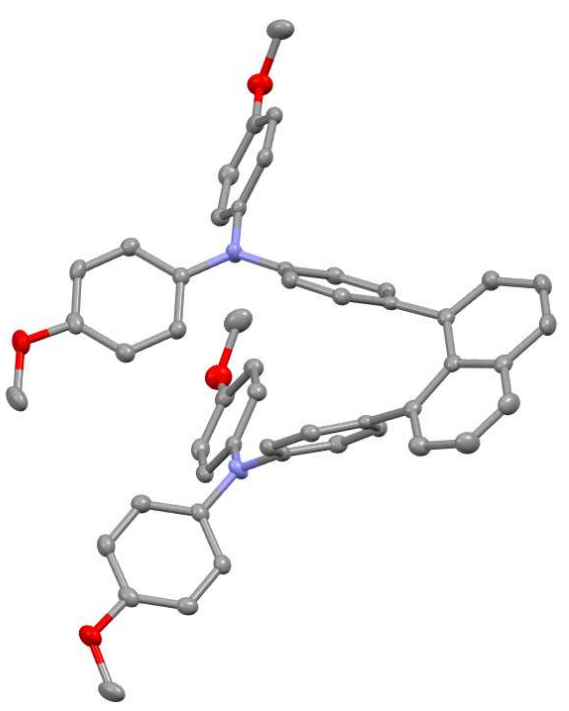

Figure 1. X-ray crystallographic structure of compound $\mathbf{( N - 1 , 8 )}$ with thermal ellipsoids drawn at the $50 \%$ probability level.

Electrochemistry. Cyclic voltammograms of the 5 compounds from Scheme 1 were measured in deaerated $\mathrm{CH}_{2} \mathrm{Cl}_{2}$ with $0.1 \mathrm{M} \mathrm{TBAPF}_{6}$ (tetra- $n$-butylammonium hexafluorophosphate) as an electrolyte, the results are shown in Figure 2. The waves at $-0.53 \mathrm{~V}$ vs. $\mathrm{Fc}^{+} / \mathrm{Fc}$ are due to decamethylferrocene which was added in small quantities for internal potential calibration. ${ }^{13}$ For compound $\mathbf{( N - 1 , 8 )}$ one observes two quasi-reversible waves between 0.1 and $0.4 \mathrm{~V}$ vs. $\mathrm{Fc}^{+} / \mathrm{Fc}$ which are caused by consecutive one-electron oxidation of each of the two triarylamino-groups. Twofold oxidation of a given triarylamine of this type requires higher potentials. ${ }^{14}$ For compounds $(\mathbf{N}-\mathbf{1 , 5})$ and $\mathbf{( N - 2 , 6 )}$ the two oneelectron oxidation processes of separate triarylamino-groups are unresolved. The half-wave potentials reported in Table 1 were determined by simulation of the experimental voltammograms (Figure S21).

The difference in half-wave potentials $(\Delta \mathrm{E})$ between one-electron oxidation of the first $\left(\mathrm{E}_{1 / 2}^{(+/ 0)}\right)$ and the second $\left(\mathrm{E}_{1 / 2}{ }^{(2+/+)}\right)$ triarylamino-group contains information about the thermodynamic stability of the 
mixed-valent monocationic forms of the molecules from Scheme 1. In principle two monocations can disproportionate to one charge-neutral and one dicationic form, and the equilibrium constant for the reverse comproportionation process $\left(\mathrm{K}_{\mathrm{c}}\right)$ is commonly used as a measure of the thermodynamic stability of a mixed-valence species. ${ }^{15}$ Based on the relation $\mathrm{K}_{\mathrm{c}}=10^{\Delta \mathrm{E} / 0.059 \mathrm{~V}}$ one obtains the values given in the last column of Table 1. The comproportionation constants of compounds $(\mathbf{N}-\mathbf{1 , 5})$ and $(\mathbf{N}-\mathbf{2 , 6 )}$ are barely above the statistical limit of 4 , and for compound $(\mathbf{N}-1,8)$ we find $K_{c}=760 \pm 360$.

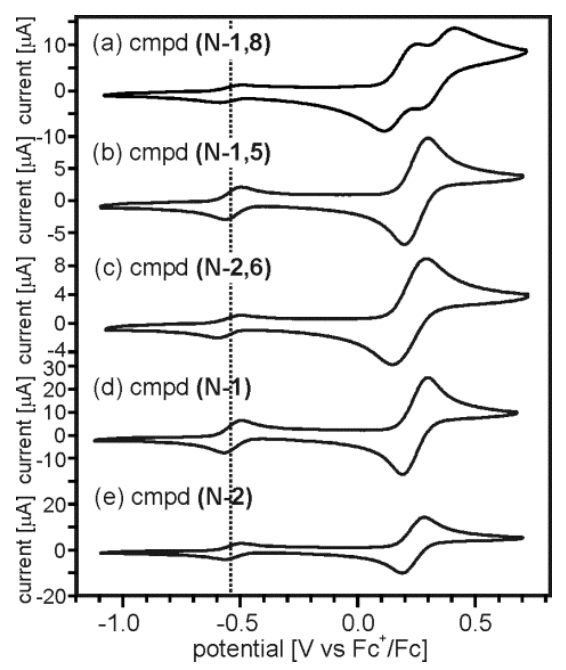

Figure 2. Cyclic voltammograms obtained in dry and de-oxygenated $\mathrm{CH}_{2} \mathrm{Cl}_{2}$ with $0.1 \mathrm{M} \mathrm{TBAPF}$ at 22 ${ }^{\circ} \mathrm{C}$. The potential sweep rate was $100 \mathrm{mV} / \mathrm{s}$. The waves at $-0.53 \mathrm{~V}$ vs. $\mathrm{Fc}^{+} / \mathrm{Fc}$ are due to decamethylferrocene which was added in small quantities for internal potential calibration.

Table 1. Half-wave potentials $\left(\mathrm{E}_{1 / 2}\right)$ in Volts vs. $\mathrm{Fc}^{+} / \mathrm{Fc}$ and comproportionation constants. ${ }^{a}$

\begin{tabular}{|l|l|l|l|}
\hline cmpd & $\mathrm{E}_{1 / 2}{ }^{(+/ 0)}$ & $\mathrm{E}_{1 / 2}^{(2+/+)}$ & $\mathrm{K}_{\mathrm{c}}$ \\
\hline $\mathbf{( N - 1 , 8 )}$ & 0.18 & 0.35 & $760 \pm 360$ \\
\hline $\mathbf{( N - 1 , 5 )}$ & 0.22 & 0.28 & $10 \pm 5$ \\
\hline $\mathbf{( N - 2 , 6 )}$ & 0.19 & 0.26 & $15 \pm 8$ \\
\hline $\mathbf{( N - 1 )}$ & 0.25 & & \\
\hline $\mathbf{( N - 2 )}$ & 0.24 & & \\
\hline
\end{tabular}


${ }^{a}$ In $\mathrm{CH}_{2} \mathrm{Cl}_{2}$ with $0.1 \mathrm{M} \mathrm{TBAPF}_{6}$ at $22{ }^{\circ} \mathrm{C}$, values extracted from simulations of voltammograms as described in the Supporting Information. Half-wave potentials are associated with experimental errors of $0.01 \mathrm{~V}$, and this defines the uncertainty in $\mathrm{K}_{\mathrm{c}}$ reported in the last column.

The magnitude of $\mathrm{K}_{\mathrm{c}}$ is governed by the superposing effects of electrostatic interaction between redox centers, ion pairing effects, and electronic communication between redox centers. ${ }^{16}$ In practice, it is tricky to disentangle the various contributions. ${ }^{17}$ In the case of our compounds it seems that the magnitude of $\mathrm{K}_{\mathrm{c}}$ is dominated by electrostatic effects because the substance with the shortest geometrical distance between redox-active groups (compound $(\mathbf{N}-\mathbf{1 , 8})$ ) has by far the largest comproportionation constant.

When using electrolyte with more weakly coordinating anions than hexafluorophosphate, ion pairing effects are expected to become less important. ${ }^{18}$ Indeed, when performing cyclic voltammetry with $\mathrm{TBA}\left[\mathrm{B}\left(\mathrm{C}_{6} \mathrm{H}_{3}\left(\mathrm{CF}_{3}\right)_{2}\right)_{4}\right]$ ("TBA $\left(\mathrm{BArF}_{24}\right)$ "), a greater splitting of the half-wave potentials $\mathrm{E}_{1 / 2}{ }^{(+/ 0)}$ and $\mathrm{E}_{1 / 2}{ }^{(2+/+)}$ is observed for compound (N-1,8) (Figure S22). Specifically, $\Delta \mathrm{E}$ increases from $170 \mathrm{mV}$ in presence of $\mathrm{TBAPF}_{6}\left(\right.$ Table 1) to $245 \mathrm{mV}$ in presence of $\mathrm{TBA}\left(\mathrm{BArF}_{24}\right)$. For compounds $(\mathbf{N}-\mathbf{1 , 5})$ and $(\mathbf{N}-$ $\mathbf{2 , 6 )}$ the two one-electron oxidation processes remain unresolved (Figure S22). 

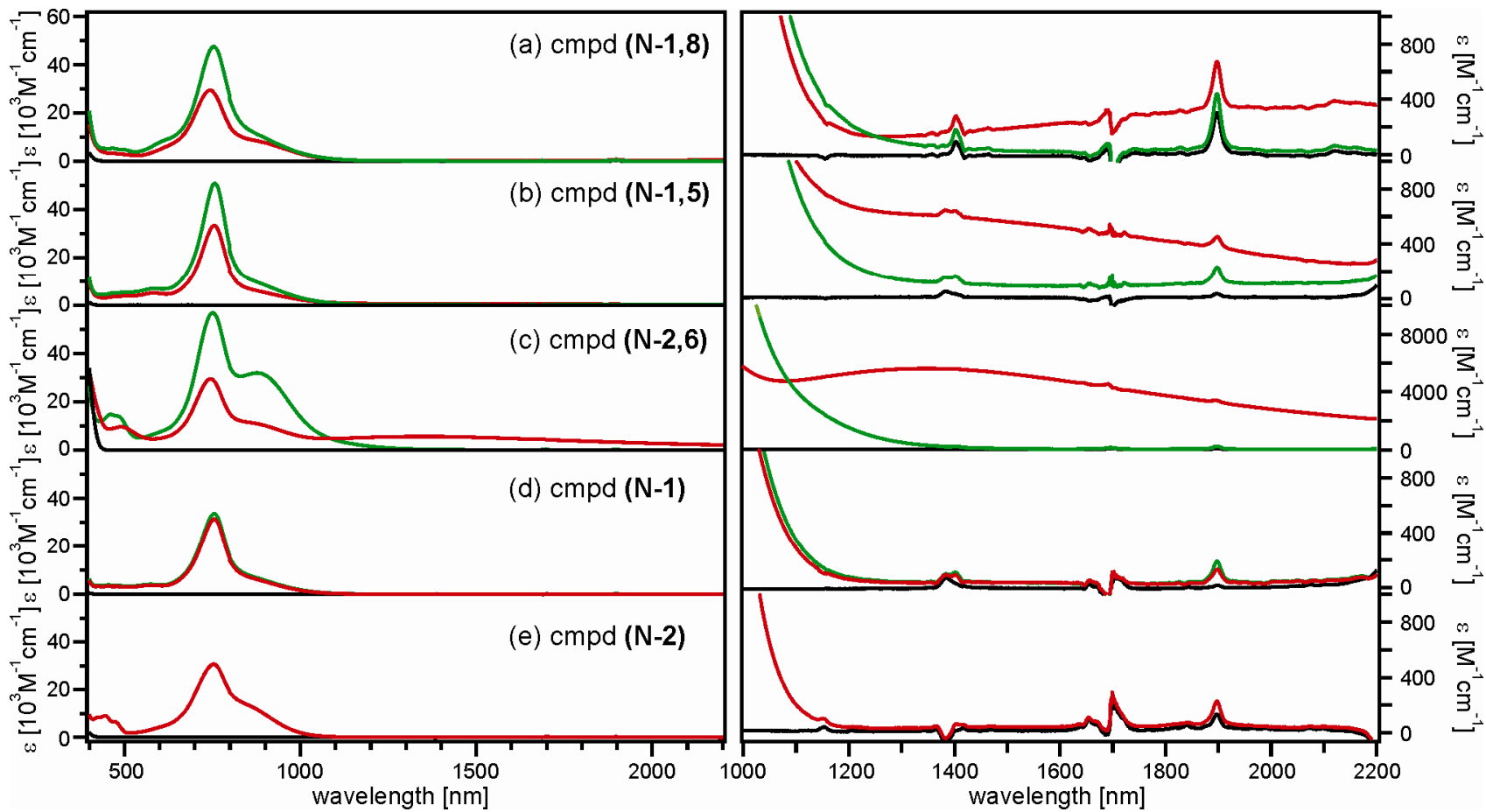

Figure 3. Optical absorption spectra recorded in $\mathrm{CH}_{2} \mathrm{Cl}_{2}$ at $22{ }^{\circ} \mathrm{C}$. Black traces: before addition of chemical oxidant (charge-neutral forms); red traces: mixed-valent monocationic forms; green traces: after addition of twice the amount of $\mathrm{SbCl}_{5}$ needed to form the mixed-valence species (dicationic forms). Note the different scales on left and right axes.

UV-Vis-NIR spectroscopy and DFT calculations. More direct information about electronic communication between redox centers can often be obtained from analysis of intervalence charge transfer (IVCT) bands of mixed valence compounds. In their charge-neutral forms, none of the 5 molecules from Scheme 1 has any electronic absorption bands at wavelengths longer than $500 \mathrm{~nm}$ (black traces in Figure 3). Upon addition of $\mathrm{SbCl}_{5}$ to solutions of compounds $(\mathbf{N}-\mathbf{1 , 8}),(\mathbf{N}-\mathbf{1 , 5}),(\mathbf{N}-\mathbf{2 , 6 )}$, (N-1), and (N-2) in $\mathrm{CH}_{2} \mathrm{Cl}_{2}$, their monocationic forms are formed in a first step. This leads to absorption bands around $750 \mathrm{~nm}$ with molar extinction coefficients on the order of $3 \cdot 10^{4} \mathrm{M}^{-1} \mathrm{~cm}^{-1}$ and weaker shoulder bands extending to $\sim 1200 \mathrm{~nm}$ (red traces in Figure 3). These absorption features are commonly observed for one-electron oxidized triarylamines, ${ }^{9 \mathrm{~g}, \mathrm{~h}, 14,19}$ and they are detected for all 5 compounds from Scheme 1. 


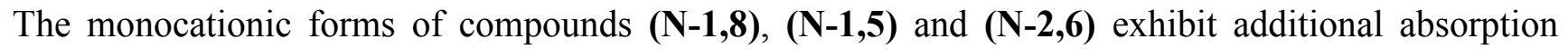
bands in the near-infrared spectral range which have significantly lower molar extinction coefficients (red traces in the right part of Figure 3). Upon addition of twice the amount of $\mathrm{SbCl}_{5}$ needed to form the monocations, $(\mathbf{N}-\mathbf{1}, \mathbf{8}),(\mathbf{N}-1,5)$, and $(\mathbf{N}-\mathbf{2}, \mathbf{6})$ are oxidized to their dicationic forms, and the respective near-infrared absorption bands disappear again (green traces in Figure 3). Evidently, the weak nearinfrared absorption bands are only present for the mixed-valent forms of the bis(triarylamine) compounds, and consequently they are attributed to IVCT bands. This assignment is in line with other studies of related organic mixed valence compounds. ${ }^{9 \mathrm{~g}, \mathrm{~h}, 20}$

The near-infrared portions of the electronic absorption spectra of the $(\mathbf{N}-\mathbf{1}, \mathbf{8})^{+},(\mathbf{N}-\mathbf{1 , 5})^{+}$, and $(\mathbf{N}-\mathbf{2}, \mathbf{6})^{+}$ monocations were analyzed by fitting multiple Gaussian functions to the experimental data (Figure S23). Multiple Gaussians were required because the abovementioned relatively intense shoulder bands tail to below $1200 \mathrm{~nm}$, and therefore partially overlap with the IVCT bands. However, the IVCT bands as such could be fitted with single Gaussians in all three cases (relevant fit parameters are summarized in Table S2). This is compatible with class II mixed valence behavior, i. e., partial delocalization of the unpaired electron on the UV-Vis-NIR timescale; complete charge delocalization (as the case in class III mixed valence compounds) would normally be expected to lead to asymmetric IVCT bands. ${ }^{20 a, 21}$

The transition dipole moment $\left(\mu_{\mathrm{ge}}\right)$ associated with the IVCT transition (in units of e. $\AA$ ) can be determined by integration of the IVCT band as described by equation $1 .{ }^{20 a, 22}$ This requires spectra represented in the form of molar extinction coefficient $\left(\mathrm{M}^{-1} \mathrm{~cm}^{-1}\right)$ versus wavenumber $\left(\mathrm{cm}^{-1}\right)$; $v_{\max }$ is the energy of the IVCT band maximum in $\mathrm{cm}^{-1}$.

$$
\mu_{g e}=0.09584 \cdot \sqrt{\frac{\int \varepsilon(v) \cdot d v}{v_{\max }}}
$$

The second column of Table 2 summarizes the transition dipole moments for the three mixed-valence 
compounds considered here. The strength of the electronic communication between redox centers (captured by the electronic coupling matrix element $\mathrm{H}_{\mathrm{AB}}$ ) is directly proportional to $\mu_{\mathrm{ge} .}{ }^{20 \mathrm{a}}$ However, calculation of $\mathrm{H}_{\mathrm{AB}}$ on the basis of $\mu_{\mathrm{ge}}$ requires knowledge of the effective electron transfer distance $\left(\mathrm{r}_{\mathrm{AB}}\right)$ which is difficult to determine, particularly in organic mixed valence compounds in which the redox activity usually cannot be pinpointed to a single atom. ${ }^{9 \mathrm{a}, \mathrm{b}}$ Consequently, we use here the transition dipole moments from Table 2 as a measure of the electronic communication between triarylamino redox centers. $^{20 \mathrm{a}, 22}$

Table 2. Geometrical N-N distance $\left(\mathrm{d}_{\mathrm{NN}}\right)^{a}$, transition dipole moment associated with the IVCT $\left(\mu_{\mathrm{ge}}\right)^{b}$, and number of C-C bonds $\left(\mathrm{n}_{\sigma}\right)$ involved in a through-bond charge transfer pathway (Scheme 2). ${ }^{c}$

\begin{tabular}{|l|l|l|l|}
\hline cmpd & $\mathrm{d}_{\mathrm{NN}}[\AA]$ & $\mu_{\text {ge }}[\mathrm{D}]$ & $\mathrm{n}_{\sigma}$ \\
\hline $\mathbf{( N - 1 , 8 ) ^ { + }}$ & 5.4 & 3.3 & N/A \\
\hline $\mathbf{( N - 1 , 5 )}^{+}$ & 14.7 & 3.7 & 11 \\
\hline $\mathbf{( N - 2 , 6 )}^{+}$ & 16.5 & 5.9 & 7 \\
\hline
\end{tabular}

${ }^{a}$ Obtained from structure optimizations of the radical monocations. ${ }^{b}$ Calculated on the basis of equation $1 .{ }^{c}$ Counted between carbon atoms at the $\alpha$-positions to the naphthylene bridge.

The $\mu_{\text {ge }}$ values of compounds $(\mathbf{N}-1,8)^{+}$and $(\mathbf{N}-1,5)^{+}$are similar $(3.3$ vs. 3.7 D) whereas that of

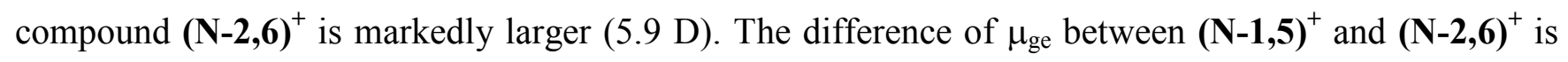
remarkable (3.7 D vs. 5.9 D) because the geometrical distance between redox centers is similar in these two compounds; the N-N distances $\left(\mathrm{d}_{\mathrm{NN}}\right)$ are 14.7 and $16.5 \AA$, respectively, based on molecular modeling (Table 2). This observation points to strongly different electronic coupling strengths $\left(\mathrm{H}_{\mathrm{AB}}\right)$ despite similar distances between redox centers in $(\mathbf{N}-\mathbf{1 , 5})^{+}$and $\left.\mathbf{( N - 2 , 6 )}\right)^{+}$. This is in line with an earlier study of naphthalene-based mixed valence compounds (albeit without a 1,8-disubstituted isomer) which found no correlation between electron transfer rate constants (which are proportional to $\mathrm{H}_{\mathrm{AB}}{ }^{2}$ ) and the 
distance between redox centers. ${ }^{4 \mathrm{a}}$ The difference in $\mu_{\mathrm{ge}}$ between $(\mathbf{N}-\mathbf{1 , 5})^{+}$and $\mathbf{( N - 2 , 6 ) ^ { + }}$ can in fact be understood on the simple basis of through-bond pathways involving a higher number of C-C bonds between redox active units in $(\mathbf{N}-\mathbf{1 , 5})^{+}$than $(\mathbf{N}-\mathbf{2 , 6})^{+} \cdot{ }^{4 a, b, 9 b}$ As illustrated by the resonance structures in Scheme $2 \mathrm{a}$, in the $\mathbf{( N - 2 , 6 ) ^ { + }}$ compound there is a through-bond pathway involving 7 covalent bonds between the carbon atoms in $\alpha$-position to the naphthylene bridge. In the $(\mathbf{N}-\mathbf{1 , 5})^{+}$isomer, the shortest through-bond pathway involves 11 covalent bonds as illustrated by the resonance structures in Scheme 2b. This simplistic picture can qualitatively explain the experimentally observed difference in $\mu_{\mathrm{ge}}$ between $(\mathbf{N}-\mathbf{1 , 5})^{+}$and $(\mathbf{N}-\mathbf{2}, \mathbf{6})^{+}$. Prior studies of naphthalene-bridged mixed valence compounds used a similar line of arguments to explain the strong dependence of electron transfer rate constants on substitution pattern. ${ }^{4} \pi$-conjugation is expected to be strongest in the $(\mathbf{N}-\mathbf{2 , 6})^{+}$compound because the equilibrium torsion angle between the naphthylene bridge and the adjacent triarylamine moiety is likely to be lower than in the case of $(\mathbf{N}-\mathbf{1 , 5})^{+}$and $(\mathbf{N}-\mathbf{1 , 8})^{+}$for steric reasons.

For the $(\mathbf{N}-1,8)^{+}$isomer no quinonoidal resonance structures that could explain an efficient throughbond charge transfer pathway can be drawn (Scheme 2c). Only resonance structures with the naphthylene bridge in a biradical state are conceivable in this case, and such structures are energetically very unfavorable. This manifests in the fact that 1,8-naphthoquinone is not a known stable molecule, contrary to 1,5- and 2,6-naphthoquinone. ${ }^{23}$ Moreover, the naphthyl biradical resonance structures in Scheme 2c leads to cross-conjugation of attached redox centers, and consequently their mutual (through-bond) electronic communication is expected to be very weak in this limit. In short, the

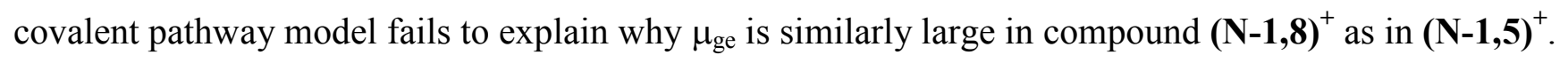

Scheme 2. Resonance structures illustrating through-bond charge transfer pathways in $(\mathbf{N}-\mathbf{2 , 6})^{+},(\mathbf{N}-$ $\mathbf{1 , 5}^{+}$, and $(\mathbf{N - 1 , 8})^{+}$. See Supporting Information page S23 for more details regarding the electronic structure of the R-substituent. 
a)
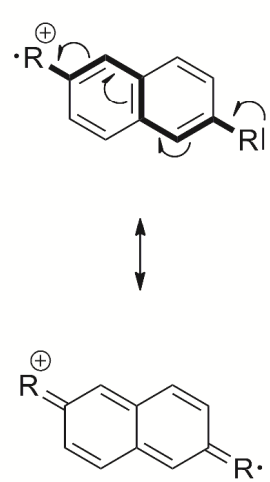

$\uparrow$

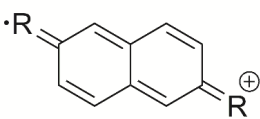

$\uparrow$

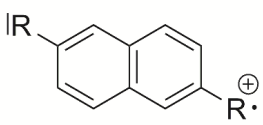

(N-2,6) b)
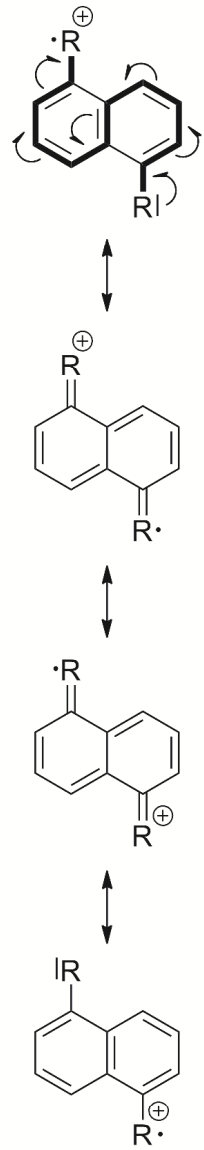

$(\mathrm{N}-1,5)$ c)
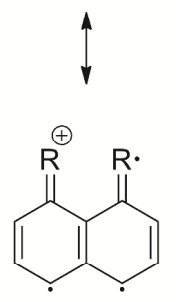

$\uparrow$

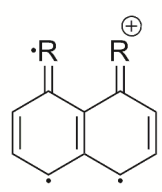

$\downarrow$

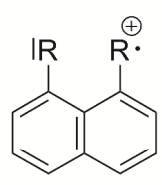

$(\mathrm{N}-1,8)$

Through-space charge transfer pathways are a viable alternative to through-bond charge transfer in compound $(\mathbf{N}-1,8)^{+}$. In the crystal structure for the charge-neutral parent compound (Figure 1) the distance between triarylamino $\mathrm{C}$-atoms which area attached to the 1- and 8-positions of the naphthalene bridge is 2.971(2) $\AA$, in the calculated structure for mixed-valent $\mathbf{( \mathbf { N } - \mathbf { 1 } , \mathbf { 8 } ) ^ { + }}$ it is $3.036 \AA$.

Thus it seems plausible that intervalence charge transfer in compound $(\mathbf{N}-\mathbf{1}, \mathbf{8})^{+}$occurs to a significant extent via a through-space pathway between the two respective triarylamino C-atoms. This hypothesis makes particular sense in view of the fact that in triarylamine radical cations significant spin density is usually located at the aryl-carbon atoms in para-position to the nitrogen center. ${ }^{24}$ For this reason, triarylamines are often equipped with substituents at the respective para-positions in order to prevent dimerization or polymerization in the course of oxidation; in other cases electropolymerization of unsubstituted triarylamines is performed intentionally. ${ }^{25}$ DFT-calculations performed at the B3LYP/6- 
$31+\mathrm{G}^{* *}$ level for $(\mathbf{N}-\mathbf{1 , 8})^{+}$lead to the conclusion that $17 \%$ of the spin density is located on the triarylamino $\mathrm{C}$ atoms in $\alpha$-position to the naphthalene bridging unit and only $2 \%$ on the naphthalene itself (Table 3). A validation of the applied functional is provided in the Supporting Information on page $\mathrm{S} 27$.

Table 3. DFT-calculated spin densities for different portions of the radical cations $(\mathbf{N}-\mathbf{1 , 8})^{+},(\mathbf{N}-\mathbf{1 , 5})^{+}$, and $(\mathbf{N}-2,6)^{+}$.

\begin{tabular}{|l|l|l|l|}
\hline & $\mathbf{( N - 1 , 8 )}^{+}$ & $\mathbf{( N - 1 , 5 )}^{+}$ & $\mathbf{( N - 2 , 6 )}^{+}$ \\
\hline triarylamine & 0.98 & 0.92 & 0.91 \\
\hline triarylamine N atoms & 0.30 & 0.28 & 0.28 \\
\hline $\begin{array}{l}\text { triarylamine C atoms in } \alpha- \\
\text { position to naphthalene }\end{array}$ & 0.17 & 0.11 & 0.12 \\
\hline naphthalene bridging unit & 0.02 & 0.08 & 0.09 \\
\hline
\end{tabular}


The TD-DFT calculations show that the SOMO of $(\mathbf{N - 1 , 8})^{+}$is strongly localized on the two triarylamino units (Table 3 and Figure 4). By contrast, the SOMOs of $(\mathbf{N}-\mathbf{1 , 5})^{+}$and $(\mathbf{N}-\mathbf{2 , 6})^{+}$show significantly stronger involvement of the naphthalene bridging unit. In the latter two compounds, $\pi$ conjugation between triarylamino units and naphthalene bridges is obviously significantly stronger than in $(\mathbf{N}-1,8)^{+}$. This observation provides additional support for the hypothesis that a through-space charge transfer pathway is important in $\mathbf{( N - 1 , 8 ) ^ { + }}$.

$(\mathrm{N}-1,8)^{+}$
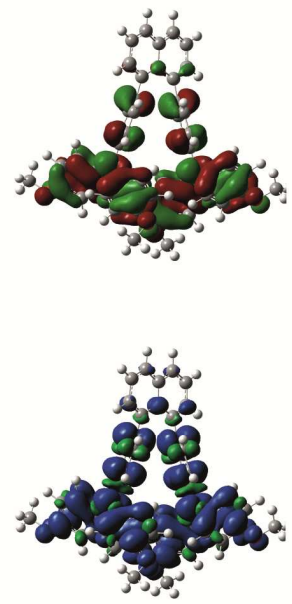

$(\mathrm{N}-1,5)^{+}$
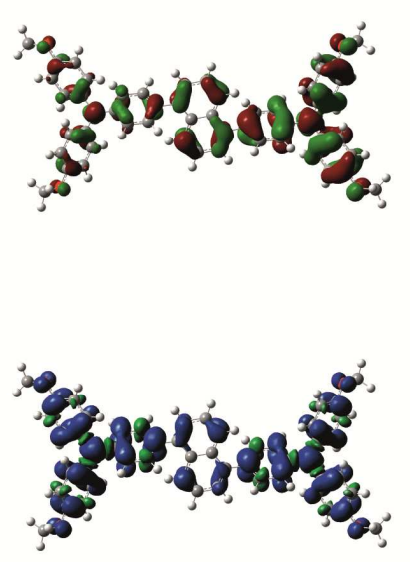

$(\mathrm{N}-2,6)^{+}$
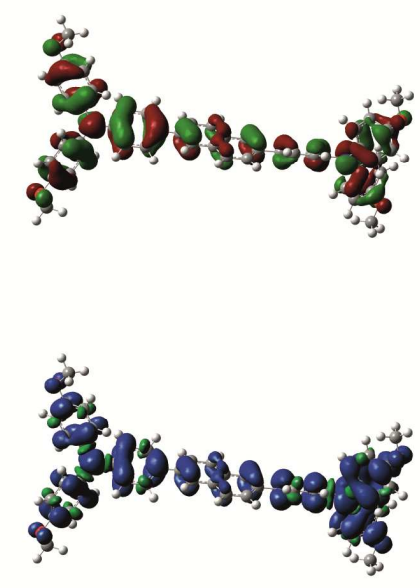

Figure 4. SOMOs (upper line) and spin density distributions (lower line) in the three mixed-valent monocations $(\mathbf{N}-\mathbf{1 , 8})^{+},(\mathbf{N}-\mathbf{1 , 5})^{+}$, and $(\mathbf{N}-\mathbf{2 , 6})^{+}$according to DFT calculations.

In order to assess to what extent thermal motions can affect the spin density distribution, the length of the C-C bond between the naphthalene bridge and the triarylamine units was varied by $\pm 0.1 \AA$ around its equilibrium position. Similarly, the torsion angle between the naphthalene plane and the adjacent phenyl plane of the triarylamine units was varied by $\pm 10^{\circ}$. The resulting spin density changes were smaller than $3 \%$ in all cases, indicating that calculations performed at equilibrium conformation can reasonably be used for interpretation of the experimental findings. In going from the neutral forms to the cations, charges redistribute evenly on the hydrogen atoms. Furthermore, calculated Mulliken charges increase 
consistently on all triarylamine $\mathrm{N}$-atoms. In compounds $(\mathbf{N}-\mathbf{1 , 5})$ and $\mathbf{( N - 2 , 6 )}$ this is accompanied by an increase of the Mulliken charges at the $\mathrm{C}$-atoms in para-position to the $\mathrm{N}$-atoms, in line with expectation.

EPR spectroscopy. The X-band EPR spectra of the mixed-valence compounds $(\mathbf{N}-\mathbf{1 , 8})^{+},(\mathbf{N}-\mathbf{1 , 5})^{+},(\mathbf{N}-$ 2,6) ${ }^{+}$measured in $\mathrm{CH}_{2} \mathrm{Cl}_{2}$ at $20{ }^{\circ} \mathrm{C}$ (solid black traces in Figure 5a-c) have been simulated (dotted red traces in Figure 5a-c) based on the interaction of the unpaired electron with two equivalent ${ }^{14} \mathrm{~N}$ atoms $\left(a_{\mathrm{N}}\right.$ of 4.3 to $\left.4.5 \mathrm{G}\right)$ and two protons. For $(\mathbf{N}-1,5)^{+}$the two protons are equivalent, whereas for $(\mathbf{N}-\mathbf{1 , 8})^{+}$ and $(\mathbf{N}-\mathbf{2 , 6})^{+}$they are non-equivalent (Table 4). Typical gyromagnetic factors $(\mathrm{g})$ for triarylamine radical cations are found (Table 4). Reference compounds $(\mathbf{N}-\mathbf{1})^{+}$and $(\mathbf{N}-2)^{+}$exhibit the expected threeline pattern (black traces in Figure 5d/e) resulting from interaction of the unpaired electron with a single ${ }^{14} \mathrm{~N}$ atom. For both reference compounds the hyperfine coupling constant $\left(a_{\mathrm{N}}=8.7 \mathrm{G}\right)$ is close to the value expected for triarylamine radical cations $(9 \mathrm{G}) .{ }^{24}$ The ${ }^{14} \mathrm{~N}$ hyperfine coupling constant of $4.5 \mathrm{G}$ for the mixed-valence compound $(\mathbf{N}-\mathbf{1 , 5})^{+}$and hyperfine interaction with two equivalent hydrogen nuclei are compatible with complete delocalization of the unpaired electron in this compound. In other words, on the EPR timescale at $20^{\circ} \mathrm{C}(\mathbf{N}-\mathbf{1 , 5})^{+}$is a class III mixed valence species. By contrast, in compounds $(\mathbf{N}-\mathbf{1 , 8})^{+}$and $(\mathbf{N}-\mathbf{2 , 6})^{+} a_{\mathrm{N}}$ is slightly smaller than $4.5 \mathrm{G}$ (Table 4), and hyperfine interaction of the unpaired electron occurs with two non-equivalent hydrogen nuclei. These combined findings are compatible with classification of $(\mathbf{N}-\mathbf{1 , 8})^{+}$and $(\mathbf{N}-\mathbf{2 , 6})^{+}$as class II or borderline class II / class III mixed valence species, respectively. 


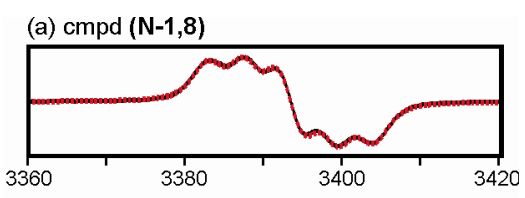

(b) cmpd (N-1,5)

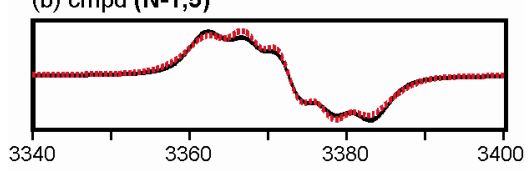

(c) cmpd (N-2,6)
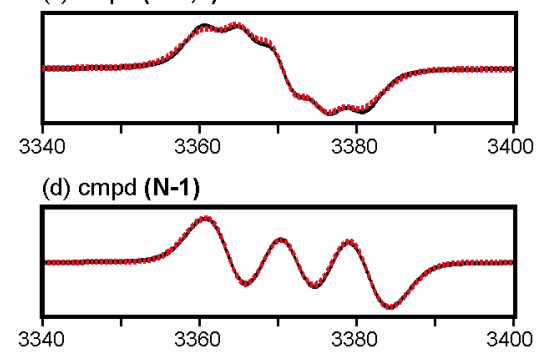

(e) cmpd (N-2)

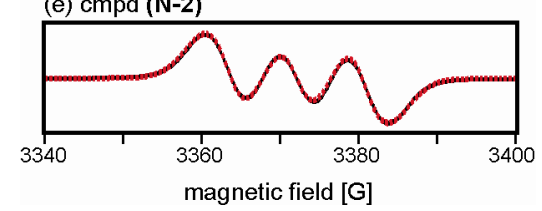

Figure 5. Experimental $\mathrm{X}$-band $\mathrm{EPR}$ spectra measured in $\mathrm{CH}_{2} \mathrm{Cl}_{2}$ at $20{ }^{\circ} \mathrm{C}$ (solid black traces) together with their simulations (dotted red traces) yielding the EPR parameters given in Table 4. The simulations were performed using the WinSim 2012 software. Microwave frequencies were: (a) $9.516901 \mathrm{GHz}$, (b) 9.458584 GHz, (c) $9.452843 \mathrm{GHz}$, (d) $9.458007 \mathrm{GHz}$, (e) $9.456722 \mathrm{GHz}$.

Table 4. EPR parameters (gyromagnetic factors and hyperfine coupling constants). ${ }^{a}$

\begin{tabular}{|l|l|l|l|l|}
\hline cmpd & $g$ & $a_{\mathrm{N}}[\mathrm{G}]$ & $a_{\mathrm{H} 1}[\mathrm{G}]$ & $a_{\mathrm{H} 2}[\mathrm{G}]$ \\
\hline $\mathbf{( N - 1 , 8 )}$ & 2.0037 & $4.3(2 \mathrm{~N})$ & 1.3 & 0.8 \\
\hline $\mathbf{( N - 1 , 5 )}^{+}$ & 2.0038 & $4.5(2 \mathrm{~N})$ & 0.9 & 0.9 \\
\hline $\mathbf{( N - 2 , 6 )}^{+}$ & 2.0036 & $4.4(2 \mathrm{~N})$ & 1.5 & 0.5 \\
\hline $\mathbf{( N - 1 )}^{+}$ & 2.0036 & $8.7(1 \mathrm{~N})$ & & \\
\hline $\mathbf{( N - 2 )}^{+}$ & 2.0036 & $8.7(1 \mathrm{~N})$ & & \\
\hline
\end{tabular}

${ }^{a}$ in $\mathrm{CH}_{2} \mathrm{Cl}_{2}$ at $20^{\circ} \mathrm{C}$. 


\section{SUMMARY AND CONCLUSIONS}

On the EPR timescale the mixed-valence compounds considered here are either completely delocalized (1,5-isomer), or they can be considered as borderline systems between class II and III $(2,6-$ isomer and 1,8-isomer). On the UV-Vis-NIR timescale they are partially delocalized class II compounds. The magnitudes of the electrochemically determined comproportionation constants seem to be dominated by electrostatic contributions. A simplistic through-bond charge transfer pathway model explains why electronic communication between triarylamine moieties in the 2,6-isomer is significantly stronger than in the 1,5-isomer but it fails to account for the behavior of the 1,8-isomer. For the latter, a through-space charge transfer pathway involving the triarylamino $\mathrm{C}$-atoms in $\alpha$-position to the naphthalene linker can provide an adequate qualitative explanation for the experimental observations. DFT calculations support this view.

It seems plausible that the through-space charge transfer pathway generally plays an important role in molecular structures based on 1,8-disubstituted naphthalene pillaring motifs.

\section{EXPERIMENTAL SECTION}

NMR spectroscopy, ESI-HRMS, elemental analysis, cyclic voltammetry, optical absorption, and EPR spectroscopy occurred using the same equipment and methods as described in detail in two recent studies. ${ }^{9 e, 26}$ Microwave frequencies in Figure 5 were: (a) $9.5169 \mathrm{GHz}$, (b) $9.4585 \mathrm{GHz}$, (c) $9.4528 \mathrm{GHz}$, (d) $9.4580 \mathrm{GHz}$, (e) $9.4567 \mathrm{GHz}$. EPR measurements were performed with a $1 \mathrm{mM}$ solution of the respective compound in $\mathrm{CH}_{2} \mathrm{Cl}_{2}$ after addition of one equivalent of $\mathrm{SbCl}_{5}$. The simulations of the EPR spectra were performed using suitable software. Geometry optimization and TD-DFT calculations were performed at the B3LYP/6-31+G** level. All calculations were made using Gaussian 09. GaussView 5.0 was used for visualization of the results. 
The $\mathrm{TBABArF}_{24}$ electrolyte was prepared as follows: Solutions of tetrabutylammonium bromide (183 $\mathrm{mg}, 0.56 \mathrm{mmol}$ ) and sodium tetrakis[3,5-bis(trifluoromethyl)-phenyl]borate (500 $\mathrm{mg}, 0.56 \mathrm{mmol})$ in 2:1 (v/v) methanol/water mixtures $(3 \mathrm{~mL}$ each) were combined. A pale yellow precipitate formed immediately. The latter was filtered off and washed with water. The solid was dissolved in methanol, and then precipitated by dropwise addition of water while stirring the solution. This procedure was repeated, and the resulting colorless needles were dried under reduced pressure to yield the pure electrolyte (463 mg, $0.42 \mathrm{mmol}, 75 \%)$.

N,N-bis(4-methhoxyphenyl)aniline (2). Commercial bis(4-methoxyphenyl)amine (1) (0.50 g, 2.18 $\mathrm{mmol}), \mathrm{NaO}{ }^{t} \mathrm{Bu}(3.14 \mathrm{~g}, 32.7 \mathrm{mmol})$ and $\mathrm{Pd}(\mathrm{dba})_{2}(50 \mathrm{mg}, 0.09 \mathrm{mmol})$ were suspended in dry toluene (12 ml) under $\mathrm{N}_{2}$ atmosphere. After bubbling $\mathrm{N}_{2}$ during 30 minutes, bromobenzene (0.23 ml, $\left.2.2 \mathrm{mmol}\right)$ and $\left[\mathrm{HP}\left({ }^{t} \mathrm{Bu}\right)_{3}\right] \mathrm{BF}_{4}(25 \mathrm{mg}, 0.09 \mathrm{mmol})$ were added, and the mixture was reacted at $85{ }^{\circ} \mathrm{C}$ overnight. After cooling to room temperature and addition of water $(20 \mathrm{ml})$, the mixture was extracted with $\mathrm{CH}_{2} \mathrm{Cl}_{2}$. The combined organic phases were washed with water and then dried over anhydrous $\mathrm{MgSO}_{4}$. The solvent was removed on a rotary evaporator, and the crude product was purified on a silica gel column with a 1:1 (v:v) mixture of pentane and $\mathrm{CH}_{2} \mathrm{Cl}_{2}$ as the eluent. The pure product was obtained as a yellowish solid (0.60 g, $1.90 \mathrm{mmol}, 90 \%) .{ }^{1} \mathrm{H}$ NMR (400 MHz, acetone-d 6$): \delta[\mathrm{ppm}]=7.19-7.15(\mathrm{~m}, 2$ H), 7.03-7.00 (m, $4 \mathrm{H}), 6.91-6.82(\mathrm{~m}, 7 \mathrm{H}), 3.78(\mathrm{~s}, 6 \mathrm{H})$.

4-Iodo-N,N-bis(4-methoxyphenyl)aniline (3). Following a previously published protocol, ${ }^{27}$ [bis(trifluoroacetoxy)iodo]benzene $(0.42 \mathrm{~g}, 0.98 \mathrm{mmol})$ and iodine $(0.25 \mathrm{~g}, 0.98 \mathrm{mmol})$ were dissolved in $\mathrm{CH}_{2} \mathrm{Cl}_{2}(10 \mathrm{ml})$ and stirred under $\mathrm{N}_{2}$ for 1 hour at room temperature in the dark. $N, N$-bis(4methoxyphenyl)aniline (2) $(0.53 \mathrm{~g}, 1.74 \mathrm{mmol})$ in $\mathrm{CH}_{2} \mathrm{Cl}_{2}(15 \mathrm{ml})$ was added, and the reaction mixture was refluxed for 1 hour. Then additional [bis(trifluoroacetoxy)iodo]benzene (0.42 g, $0.98 \mathrm{mmol})$ and iodine $(0.25 \mathrm{~g}, 0.98 \mathrm{mmol})$ were added, and refluxing was continued for 1 hour. After cooling to room temperature, saturated aqueous $\mathrm{Na}_{2} \mathrm{~S}_{2} \mathrm{O}_{3}$ solution $(30 \mathrm{ml})$ was added, and the mixture was extracted with $\mathrm{CH}_{2} \mathrm{Cl}_{2}$. The combined organic phases were dried over anhydrous $\mathrm{MgSO}_{4}$ and the solvents were 
evaporated. Column chromatography on silica gel with a mixture of pentane and $\mathrm{CH}_{2} \mathrm{Cl}_{2}$ (ranging from 5:1 to $1: 1(\mathrm{v}: \mathrm{v})$ in composition) yielded the product as a yellowish solid $(0.68 \mathrm{~g}, 1.57 \mathrm{mmol}, 90 \%) .{ }^{1} \mathrm{H}$ NMR (400 MHz, acetone-d $\left.)_{6}\right): \delta[p p m]=7.47-7.45(\mathrm{~m}, 2 \mathrm{H})$, 7.07-7.05 (m, $\left.4 \mathrm{H}\right)$, 6.93-6.90 (m, $\left.4 \mathrm{H}\right)$, 6.64-6.62 (m, $2 \mathrm{H}), 3.79$ (s, $6 \mathrm{H})$.

Compound 4. Following a previously published method, ${ }^{10} 4$-iodo- $N, N$-bis(4-methoxyphenyl)aniline (3) $(0.62 \mathrm{~g}, 1.44 \mathrm{mmol})$ was dissolved in dry THF (23 mL) under $\mathrm{N}_{2}$. After cooling to $-78{ }^{\circ} \mathrm{C}, n$-BuLi (2.5 $\mathrm{M}$ in hexane, $0.63 \mathrm{ml} 1.58 \mathrm{mmol})$ was added dropwise, and the mixture was stirred at $-78^{\circ} \mathrm{C}$ for 1 hour. 2-isopropoxy-4,4,5,5-tetramethyl-1,3,2-dioxaborolane (1.00 ml, $4.92 \mathrm{mmol})$ was added dropwise, and stirring at $-78{ }^{\circ} \mathrm{C}$ was continued for 1 hour prior to stirring at room temperature overnight. After addition of water $(15 \mathrm{ml})$ the mixture was extracted with $\mathrm{CH}_{2} \mathrm{Cl}_{2}$. The combined organic phases were dried over anhydrous $\mathrm{MgSO}_{4}$ and the solvents were evaporated. Column chromatography on a silica gel stationary phase with a 5:1 (v:v) pentane $/ \mathrm{CH}_{2} \mathrm{Cl}_{2}$ mixture afforded the product as a white solid (1.05 g, $2.74 \mathrm{mmol}, 75 \%) .{ }^{1} \mathrm{H}$ NMR $\left(400 \mathrm{MHz}, \mathrm{CDCl}_{3}\right): \delta[\mathrm{ppm}]=7.61-7.58(\mathrm{~m}, 2 \mathrm{H}), 7.08-7.04(\mathrm{~m}, 4 \mathrm{H}), 6.88-$ $6.81(\mathrm{~m}, 6 \mathrm{H}), 3.80(\mathrm{~s}, 6 \mathrm{H}), 1.31(\mathrm{~s}, 12 \mathrm{H})$.

1,5-Diiodonaphthalene (6). The synthesis of this compound followed a previously reported protocol. ${ }^{2 b}$ To a suspension of 1,5-diaminonaphthalene (5) (2.00 g, $12.6 \mathrm{mmol})$ in $\mathrm{H}_{2} \mathrm{SO}_{4}(6.9 \mathrm{M}, 100 \mathrm{ml})$ at $-20{ }^{\circ} \mathrm{C}$ was added an aqueous solution of $\mathrm{NaNO}_{2}(2.60 \mathrm{~g}, 37.7 \mathrm{mmol}$ in $5 \mathrm{ml})$. Subsequently, an aqueous solution of KI (12.8 g, $77.1 \mathrm{mmol}$ in $10 \mathrm{ml})$ was added dropwise, and the reaction mixture was heated to $80{ }^{\circ} \mathrm{C}$ for 5 minutes. After cooling to room temperature, the solution was neutralized with solid $\mathrm{NaOH}$ and extracted with $\mathrm{CH}_{2} \mathrm{Cl}_{2}$. The combined organic phases were washed three times with aqueous $\mathrm{HCl}$ $(10 \%)$, saturated aqueous $\mathrm{Na}_{2} \mathrm{~S}_{2} \mathrm{O}_{3}$ solution, and $1 \mathrm{M}$ aqueous $\mathrm{NaOH}$ solution. The organic solvent was evaporated after drying over anhydrous $\mathrm{Na}_{2} \mathrm{SO}_{4}$. The product was obtained as a red solid (1.47 $\mathrm{g}, 3.88$ mmol, 31\%). ${ }^{1} \mathrm{H}$ NMR (400 MHz, $\left.\mathrm{CD}_{2} \mathrm{Cl}_{2}\right): \delta[\mathrm{ppm}]=8.19-8.11(\mathrm{~m}, 4 \mathrm{H}), 7.28(\mathrm{dd}, J=8.4,7.3 \mathrm{~Hz}, 2$ H).

Compound (N-1,5). 1,5-Diiodonaphthalene (6) (90 mg, $0.24 \mathrm{mmol})$, boronic ester 4 (205 mg, 0.47 
mmol $)$ and $\mathrm{Na}_{2} \mathrm{CO}_{3}(0.38 \mathrm{~g}, 3.59 \mathrm{mmol})$ were dissolved in a mixture of THF $(8 \mathrm{ml})$ and de-ionized water (6 ml). After bubbling $\mathrm{N}_{2}$ for 10 minutes, $\mathrm{Pd}\left(\mathrm{PPh}_{3}\right)_{4}(15 \mathrm{mg}, 13 \mu \mathrm{mol})$ was added and bubbling was continued for 5 minutes. Then the reaction mixture was heated to reflux overnight. Water (10 ml) was added after cooling to room temperature, and the mixture was extracted with $\mathrm{CH}_{2} \mathrm{Cl}_{2}$. The combined organic phases were dried over anhydrous $\mathrm{Na}_{2} \mathrm{SO}_{4}$ and evaporated. Chromatography on silica gel column with a 1:1 pentane $/ \mathrm{CH}_{2} \mathrm{Cl}_{2}$ mixture yielded the product as a yellow solid (150 mg, 0.20 mmol, 83\%), mp: $218-222{ }^{\circ} \mathrm{C} .{ }^{1} \mathrm{H}$ NMR (400 MHz, $\left.\mathrm{CD}_{2} \mathrm{Cl}_{2}\right): \delta[\mathrm{ppm}]=7.98(\mathrm{dd}, J=7.9,1.3 \mathrm{~Hz}, 2 \mathrm{H})$, 7.49-7.39 (m, 4 H), 7.35-7.27 (m, 4 H), 7.19-7.10 (m, 8 H), 7.05-6.98 (m, 4 H), 6.93-6.84 (m, 8 H), 3.80 $(\mathrm{s}, 12 \mathrm{H}) .{ }^{13} \mathrm{C}$ NMR $\left(100 \mathrm{MHz}, \mathrm{CD}_{2} \mathrm{Cl}_{2}\right): \delta[\mathrm{ppm}]=156.7,148.7,141.5,141.0,132.8,131.2,127.3$, 127.2, 125.9, 125.8, 120.4, 115.3, 56.0. HRMS (ESI TOF) m/z: [M] Calcd for $\mathrm{C}_{50} \mathrm{H}_{42} \mathrm{~N}_{2} \mathrm{O}_{4}$ 734.3139; Found 734.3152. Anal. Calcd for $\mathrm{C}_{50} \mathrm{H}_{42} \mathrm{~N}_{2} \mathrm{O}_{4} \cdot \mathrm{H}_{2} \mathrm{O}$ : C, 79.76; H, 5.89; N, 3.72. Found: C, 79.78; H, 5.85; N, 3.91. Evidence for water is also present in the ${ }^{1} \mathrm{H}$ NMR spectrum, see Supporting Information. 1,8-Diiodonaphthalene (8). The synthesis of this compound followed a previously reported protocol. ${ }^{2 \mathrm{~b}}$ To a suspension of $\mathrm{NaNO}_{2}(2.50 \mathrm{~g}, 36.2 \mathrm{mmol})$ in conc. $\mathrm{H}_{2} \mathrm{SO}_{4}(25 \mathrm{ml})$ at $0{ }^{\circ} \mathrm{C}$ was added dropwise a solution of 1,8-diaminonaphthalene (7) $(2.50 \mathrm{~g}, 15.8 \mathrm{mmol})$ in glacial acetic acid (25 ml). The mixture was stirred for 15 minutes prior to adding ice $(30 \mathrm{~g})$ and urea $(0.20 \mathrm{~g})$. Subsequently, aqueous KI solution (35 g, $211 \mathrm{mmol}$ in $35 \mathrm{ml}$ ) was added dropwise. After stirring at room temperature for 4 hours, the reaction mixture was extracted with $\mathrm{CH}_{2} \mathrm{Cl}_{2}$. The combined organic phases were washed three times with aqueous $\mathrm{HCl}(10 \%)$, saturated aqueous $\mathrm{Na}_{2} \mathrm{~S}_{2} \mathrm{O}_{3}$ solution, and $1 \mathrm{M}$ aqueous $\mathrm{NaOH}$ solution. The solvents were evaporated after drying over anhydrous $\mathrm{MgSO}_{4}$. Column chromatography on silica gel with a 5:1 (v:v) mixture of pentane and $\mathrm{CH}_{2} \mathrm{Cl}_{2}$ afforded the product as a yellow solid (1.03 $\mathrm{g}, 2.71$ mmol, 17\%). ${ }^{1} \mathrm{H}$ NMR (400 MHz, $\left.\mathrm{CD}_{2} \mathrm{Cl}_{2}\right): \delta[\mathrm{ppm}]=8.43(\mathrm{dd}, J=7.3,1.2 \mathrm{~Hz}, 2 \mathrm{H}), 7.85(\mathrm{dd}, J=8.2$, $1.3 \mathrm{~Hz}, 2 \mathrm{H}), 7.08(\mathrm{dd}, J=8.2,7.3 \mathrm{~Hz}, 2 \mathrm{H})$.

Compound (N-1,8). 1,8-Diiodonapthalene (8) (60 mg, $0.16 \mathrm{mmol}$ ), compound 4 (150 mg, 0.35 $\mathrm{mmol})$, and $\mathrm{Na}_{2} \mathrm{CO}_{3}(0.25 \mathrm{~g}, 2.36 \mathrm{mmol})$ were dissolved in a mixture of THF $(5 \mathrm{ml})$ and water $(4 \mathrm{ml})$. 
After bubbling $\mathrm{N}_{2}$ gas for 10 minutes, $\mathrm{Pd}\left(\mathrm{PPh}_{3}\right)_{4}(10 \mathrm{mg}, 8.65 \mu \mathrm{mol})$ was added and bubbling was continued for 5 minutes. The reaction mixture was refluxed under $\mathrm{N}_{2}$ overnight. After cooling to room temperature, water $(15 \mathrm{ml})$ was added and the mixture was extracted with $\mathrm{CH}_{2} \mathrm{Cl}_{2}$. The combined organic phases were dried over anhydrous $\mathrm{MgSO}_{4}$ and evaporated. Chromatography on silica gel column with a 2:3(v:v) mixture of pentane and $\mathrm{CH}_{2} \mathrm{Cl}_{2}$ afforded the product as an orange solid (70 $\mathrm{mg}$, $0.09 \mathrm{mmol}, 58 \%$ ), mp: $238-241{ }^{\circ} \mathrm{C} .{ }^{1} \mathrm{H}$ NMR $\left(400 \mathrm{MHz}, \mathrm{CDCl}_{3}\right): \delta[\mathrm{ppm}]=7.88(\mathrm{dd}, J=8.2,1.4 \mathrm{~Hz}, 2$ H), $7.52(\mathrm{dd}, J=8.2,7.1 \mathrm{~Hz}, 2 \mathrm{H}), 7.42(\mathrm{dd}, J=7.1,1.4 \mathrm{~Hz}, 2 \mathrm{H}), 7.14-7.10(\mathrm{~m}, 8 \mathrm{H}), 6.83-6.77$ (m, 12 $\mathrm{H}), 6.71-6.68(\mathrm{~m}, 4 \mathrm{H}), 3.79(\mathrm{~s}, 12 \mathrm{H}) .{ }^{13} \mathrm{C} \mathrm{NMR}\left(100 \mathrm{MHz}, \mathrm{CD}_{2} \mathrm{Cl}_{2}\right): \delta[\mathrm{ppm}]=156.3,147.0,141.5$, 141.1, 136.3, 136.2, 130.9 130.8, 130.1, 128.3, 127.1, 125.7, 119.6, 115.1, 56.0. HRMS (ESI TOF) m/z: $[\mathrm{M}]^{+}$Calcd for $\mathrm{C}_{50} \mathrm{H}_{42} \mathrm{~N}_{2} \mathrm{O}_{4}$ 734.3139; Found 734.3146. Anal. Calcd for $\mathrm{C}_{50} \mathrm{H}_{42} \mathrm{~N}_{2} \mathrm{O}_{4} \cdot 2 \mathrm{H}_{2} \mathrm{O}$ : C, 77.90; $\mathrm{H}$, 6.01; N, 3.63. Found: 78.06; H, 5.85; N, 3.56. Evidence for water is also present in the ${ }^{1} \mathrm{H}$ NMR spectrum, see Supporting Information.

Compound (N-2,6). Commercial 2,6-dibromonaphthalene (9) (68 mg, $0.24 \mathrm{mmol}$ ), compound 4 (225 $\mathrm{mg}, 0.52 \mathrm{mmol})$, and $\mathrm{Na}_{2} \mathrm{CO}_{3}(0.40 \mathrm{~g}, 3.77 \mathrm{mmol})$ were dissolved in a mixture of $\mathrm{THF}(8 \mathrm{ml})$ and water (6 ml). After bubbling $\mathrm{N}_{2}$ gas during 10 minutes, $\mathrm{Pd}\left(\mathrm{PPh}_{3}\right)_{4}(15 \mathrm{mg}, 13 \mu \mathrm{mol})$ was added and bubbling was continued for 5 minutes. The reaction mixture was refluxed under $\mathrm{N}_{2}$ overnight. After cooling to room temperature, water $(10 \mathrm{ml})$ was added and the mixture was extracted with $\mathrm{CH}_{2} \mathrm{Cl}_{2}$. The combined organic phases were evaporated after drying over anhydrous $\mathrm{MgSO}_{4}$. Column chromatography on silica gel with a 2:3 (v:v) mixture of pentane and $\mathrm{CH}_{2} \mathrm{Cl}_{2}$ gave the product as a colorless solid (136 $\mathrm{mg}, 0.19$ mmol, 76\%), mp: $157-160{ }^{\circ} \mathrm{C} .{ }^{1} \mathrm{H}$ NMR $\left(500 \mathrm{MHz}, \mathrm{DMSO}-\mathrm{d}_{6}, 70{ }^{\circ} \mathrm{C}\right): \delta[\mathrm{ppm}]=8.09(\mathrm{~d}, J=1.8 \mathrm{~Hz}, 2$ H), $7.96(\mathrm{~d}, J=8.6 \mathrm{~Hz}, 2 \mathrm{H}), 7.78(\mathrm{dd}, J=8.6,1.8 \mathrm{~Hz}, 2 \mathrm{H}), 7.68-7.62(\mathrm{~m}, 4 \mathrm{H}), 7.11-7.04(\mathrm{~m}, 8 \mathrm{H})$, 6.98-6.87 (m, $12 \mathrm{H}), 3.77(\mathrm{~s}, 12 \mathrm{H}) .{ }^{13} \mathrm{C}$ NMR (125 MHz, DMSO-d $\left.6,70{ }^{\circ} \mathrm{C}\right): \delta[\mathrm{ppm}]=155.7,147.8$, 139.9, 136.7, 132.1, 131.3, 128.2, 127.2, 126.4, 124.8, 123.4, 119.6, 114.8, 55.1. HRMS (ESI TOF) m/z: $[M]^{+}$Calcd for $\mathrm{C}_{50} \mathrm{H}_{42} \mathrm{~N}_{2} \mathrm{O}_{4}$ 734.3139; Found 734.3148. Anal. Calcd for $\mathrm{C}_{50} \mathrm{H}_{42} \mathrm{~N}_{2} \mathrm{O}_{4} \cdot \mathrm{H}_{2} \mathrm{O}$ : C, 79.76; H, 5.89; N, 3.72. Found: C, 80.24; H, 5.79; N, 3.84. Evidence for water is also present in the ${ }^{1} \mathrm{H}$ 
NMR spectrum, see Supporting Information.

Compound (N-1). Commercial 1-bromonaphthalene (10) (150 mg, $0.72 \mathrm{mmol})$, compound 4 (297 mg, $0.69 \mathrm{mmol})$, and $\mathrm{Na}_{2} \mathrm{CO}_{3}(0.60 \mathrm{~g}, 5.66 \mathrm{mmol})$ were dissolved in a mixture of THF $(13 \mathrm{ml})$ and water $(9$ $\mathrm{ml})$. After bubbling $\mathrm{N}_{2}$ gas during 10 minutes, $\mathrm{Pd}\left(\mathrm{PPh}_{3}\right)_{4}(22 \mathrm{mg}, 19 \mu \mathrm{mol})$ was added and bubbling was continued for 5 minutes. The reaction mixture was refluxed under $\mathrm{N}_{2}$ overnight. After cooling to room temperature, water $(10 \mathrm{ml})$ was added and the mixture was extracted with $\mathrm{CH}_{2} \mathrm{Cl}_{2}$. The combined organic phases were evaporated after drying over anhydrous $\mathrm{MgSO}_{4}$. Column chromatography on silica gel with a 2:3 (v:v) mixture of pentane and $\mathrm{CH}_{2} \mathrm{Cl}_{2}$ gave the product as a light yellow solid $(250 \mathrm{mg}$, $0.58 \mathrm{mmol}, 84 \%), \mathrm{mp}: 145-148{ }^{\circ} \mathrm{C} .{ }^{1} \mathrm{H}$ NMR $\left(400 \mathrm{MHz}\right.$, acetone-d $\left.\mathrm{d}_{6}\right): \delta[\mathrm{ppm}]=8.02-7.93(\mathrm{~m}, 2 \mathrm{H})$, $7.88(\mathrm{dt}, J=8.3,1.1 \mathrm{~Hz}, 1 \mathrm{H}), 7.58-7.45(\mathrm{~m}, 3 \mathrm{H}), 7.42(\mathrm{dd}, J=7.1,1.3 \mathrm{~Hz}, 1 \mathrm{H}), 7.36-7.28(\mathrm{~m}, 2 \mathrm{H})$, 7.19-7.10 (m, $4 \mathrm{H}), 7.03-6.90(\mathrm{~m}, 6 \mathrm{H}), 3.80(\mathrm{~s}, 6 \mathrm{H}) .{ }^{13} \mathrm{C}$ NMR $(100 \mathrm{MHz}$, acetone-d 6$): \delta[\mathrm{ppm}]=$ $157.5,149.4,141.8,141.1,135.2,133.2,132.7,131.5,129.4,128.2,128.0,127.7,126.9,126.8(2)$, 126.7(6), 126.6, 115.9, 55.9. HRMS (ESI TOF) m/z: $[\mathrm{M}]^{+}$Calcd for $\mathrm{C}_{30} \mathrm{H}_{25} \mathrm{NO}_{2} 431.1880$; Found 431.1882. Anal. Calcd for for $\mathrm{C}_{30} \mathrm{H}_{25} \mathrm{NO}_{2}$ : C, 83.50; H, 5.84; N, 3.25. Found: C, 83.35; H, 5.95; N, 3.26.

Compound (N-2). Commercial 2-bromonaphthalene (11) (75.0 mg, $0.36 \mathrm{mmol})$, compound 4 (150 $\mathrm{mg}, 0.35 \mathrm{mmol})$, and $\mathrm{Na}_{2} \mathrm{CO}_{3}(0.30 \mathrm{~g}, 2.83 \mathrm{mmol})$ were dissolved in a mixture of THF $(7 \mathrm{ml})$ and water (5 ml). After bubbling $\mathrm{N}_{2}$ gas during 10 minutes, $\mathrm{Pd}\left(\mathrm{PPh}_{3}\right)_{4}(12 \mathrm{mg}, 10 \mu \mathrm{mol})$ was added and bubbling was continued for 5 minutes. The reaction mixture was refluxed under $\mathrm{N}_{2}$ overnight. After cooling to room temperature, water $(10 \mathrm{ml})$ was added and the mixture was extracted with $\mathrm{CH}_{2} \mathrm{Cl}_{2}$. The combined organic phases were evaporated after drying over anhydrous $\mathrm{MgSO}_{4}$. Column chromatography on silica gel with a 2:3 (v:v) mixture of pentane and $\mathrm{CH}_{2} \mathrm{Cl}_{2}$ gave the product as a light yellow solid (146 mg, $0.34 \mathrm{mmol}, 97 \%), \mathrm{mp}: 124-126{ }^{\circ} \mathrm{C} .{ }^{1} \mathrm{H}$ NMR (400 MHz, acetone-d $\left.)\right): \delta[\mathrm{ppm}]=8.13-8,07(\mathrm{~m}, 1 \mathrm{H})$, 7.95-7.85 (m, 3H), 7.79 (dd, $J=8.6,1.9 \mathrm{~Hz}, 1 \mathrm{H}), 7.69-7.60(\mathrm{~m}, 2 \mathrm{H}), 7.54-7.42(\mathrm{~m}, 2 \mathrm{H}), 7.14-7.05$ (m, $4 \mathrm{H}), 7.00-6.88(\mathrm{~m}, 6 \mathrm{H}), 3.80(\mathrm{~s}, 6 \mathrm{H}) .{ }^{13} \mathrm{C} \mathrm{NMR}(100 \mathrm{MHz}$, acetone-d 6$): \delta[\mathrm{ppm}]=157.5,149.6$, $141.7,139.0,135.1,133.5,133.3,129.4,129.1,128.7,128.6,127.9,127.3,126.7,126.0,125.3,121.2$, 
115.9, 55.9. HRMS (ESI TOF) m/z: $[\mathrm{M}]^{+}$Calcd for $\mathrm{C}_{30} \mathrm{H}_{25} \mathrm{NO}_{2}$ 431.1880; Found 431.1876. Anal. Calcd for for $\mathrm{C}_{30} \mathrm{H}_{25} \mathrm{NO}_{2}: \mathrm{C}, 83.50 ; \mathrm{H}, 5.84 ; \mathrm{N}, 3.25$. Found: C, 83.08; H, 5.94; N, 3.23 .

1

2

3

4

5

6

7

8

9

10

11

12

13

14

15

16

17

18

19

20

21

22

23

24

25

26

27

28

29

30

31

32

33

34

35

36

37

38

39

40

41

42

43

44

45

46

47

48

49

50

51

52

53

54

55

56

57

58

59

60 


\section{ACKNOWLEDGMENT}

This work was supported by the Swiss NSF through grant number 200021_146231/1 and the NCCR Molecular Systems Engineering. C. G. P. acknowledges a R'Equip grant from the Swiss NSF for the EPR spectrometer. Dr. Christof Sparr and Dr. Mike Devereux are acknowledged for useful discussions.

\section{SUPPORTING INFORMATION PARAGRAPH}

${ }^{1} \mathrm{H}$ and ${ }^{13} \mathrm{C}$ NMR spectra, ESI-HRMS spectra, documentation from elemental analyses, additional electrochemical and optical spectroscopic data, computational data, crystallographic information. This material is available free of charge via the Internet at http://pubs.acs.org.

\section{REFERENCES}

(1) (a) Helms, A.; Heiler, D.; McLendon, G., J. Am. Chem. Soc. 1992, 114, 6227. (b) Weiss, E. A.; Ahrens, M. J.; Sinks, L. E.; Gusev, A. V.; Ratner, M. A.; Wasielewski, M. R., J. Am. Chem. Soc. 2004, 126, 5577. (c) Welter, S.; Lafolet, F.; Cecchetto, E.; Vergeer, F.; De Cola, L., ChemPhysChem 2005, 6, 2417. (d) Atienza-Castellanos, C.; Wielopolski, M.; Guldi, D. M.; van der Pol, C.; Bryce, M. R.; Filippone, S.; Martín, N., Chem. Commun. 2007, 5164. (e) Lörtscher, E.; Elbing, M.; Tschudy, M.; von Hänisch, C.; Weber, H. B.; Mayor, M.; Riel, H., ChemPhysChem 2008, 9, 2252. (f) Eng, M. P.; Albinsson, B., Chem. Phys. 2009, 357, 132. (g) Wenger, O. S., Chem. Soc. Rev. 2011, 40, 3538.

(2) (a) Kilså, K.; Kajanus, J.; Macpherson, A. N.; Mårtensson, J.; Albinsson, B., J. Am. Chem. Soc. 2001, 123, 3069. (b) Rodriguez, J. G.; Tejedor, J. L., J. Org. Chem. 2002, 67, 7631. (c) Benniston, A. C.; Harriman, A.; Rewinska, D. B.; Yang, S.; Zhi, Y. G., Chem.-Eur. J. 2007, 13, 10194. (d) Cramer, J. R.; Ning, Y. X.; Shen, C.; Nuermaimaiti, A.; Besenbacher, F.; Linderoth, T. R.; Gothelf, K. V., Eur. J. 
Org. Chem. 2013, 2813. (e) Benniston, A. C.; Clift, S.; Hagon, J.; Lemmetyinen, H.; Tkachenko, N. V.; Clegg, W.; Harrington, R. W., ChemPhysChem 2012, 13, 3672.

(3) Lotter, D.; Neuburger, M.; Rickhaus, M.; Häussinger, D.; Sparr, C., Angew. Chem. Int. Ed. 2016, doi: 10.1002/anie.201510259.

(4) (a) Nelsen, S. F.; Konradsson, A. E.; Teki, Y., J. Am. Chem. Soc. 2006, 128, 2902. (b) Nelsen, S. F.; Weaver, M. N.; Konradsson, A. E.; Telo, J. P.; Clark, T., J. Am. Chem. Soc. 2004, 126, 15431. (c) Nelsen, S. F.; Konradsson, A. E.; Weaver, M. N.; Telo, J. P., J. Am. Chem. Soc. 2003, 125, 12493. (d) Nelsen, S. F.; Weaver, M. N.; Zink, J. I.; Telo, J. P., J. Am. Chem. Soc. 2005, 127, 10611.

(5) (a) Nöll, G.; Avola, M., J. Phys. Org. Chem. 2006, 19, 238. (b) Rovira, C.; Ruiz-Molina, D.; Elsner, O.; Vidal-Gancedo, J.; Bonvoisin, J.; Launay, J.-P.; Veciana, J., Chem. Eur. J. 2001, 7, 240.

(6) (a) Sangtarash, S.; Huang, C. C.; Sadeghi, H.; Sorohhov, G.; Hauser, J.; Wandlowski, T.; Hong, W. J.; Decurtins, S.; Liu, S. X.; Lambert, C. J., J. Am. Chem. Soc. 2015, 137, 11425. (b) Yoshizawa, K., Acc. Chem. Res. 2012, 45, 1612. (c) Launay, J. P., Polyhedron 2015, 86, 151.

(7) (a) McAdam, C. J.; Brunton, J. J.; Robinson, B. H.; Simpson, J., J. Chem. Soc., Dalton Trans. 1999, 2487. (b) Arnold, R.; Matchett, S. A.; Rosenblum, M., Organometallics 1988, 7, 2261. (c) Arnold, R.; Foxman, B. M.; Rosenblum, M.; Euler, W. B., Organometallics 1988, 7, 1253.

(8) Kang, Y. K.; Rubtsov, I. V.; Iovine, P. M.; Chen, J. X.; Therien, M. J., J. Am. Chem. Soc. 2002, 124,8275 .

(9) (a) Heckmann, A.; Lambert, C., Angew. Chem. Int. Ed. 2012, 51, 326. (b) Hankache, J.; Wenger, O. S., Chem. Rev. 2011, 111, 5138. (c) Bischof, A. M.; Zhang, S. P.; Meyer, T. Y.; Lear, B. J., J. Phys. Chem. C 2014, 118, 12693. (d) Jahnke, A. C.; Proppe, J.; Spulber, M.; Palivan, C. G.; Herrmann, C.; Wenger, O. S., J. Phys. Chem. A 2014, 118, 11293. (e) Reuter, L. G.; Bonn, A. G.; Stückl, A. C.; He, B. C.; Pati, P. B.; Zade, S. S.; Wenger, O. S., J. Phys. Chem. A 2012, 116, 7345. (f) Barlow, S.; Risko, C.; 
Chung, S. J.; Tucker, N. M.; Coropceanu, V.; Jones, S. C.; Levi, Z.; Brédas, J. L.; Marder, S. R., J. Am. Chem. Soc. 2005, 127, 16900. (g) Lambert, C.; Nöll, G.; Schelter, J., Nat. Mater. 2002, 1, 69. (h) Lambert, C.; Amthor, S.; Schelter, J., J. Phys. Chem. A 2004, 108, 6474.

(10) Yu, L. H.; Xi, J. Y.; Chan, H. T.; Su, T.; Antrobus, L. J.; Tong, B.; Dong, Y. P.; Chan, W. K.; Phillips, D. L., J. Phys. Chem. C 2013, 117, 2041.

(11) Clough, R. L.; Kung, W. J.; Marsh, R. E.; Roberts, J. D., J. Org. Chem. 1976, 41, 3603.

(12) (a) Zheng, S. J.; Barlow, S.; Risko, C.; Kinnibrugh, T. L.; Khrustalev, V. N.; Jones, S. C.; Antipin, M. Y.; Tucker, N. M.; Timofeeva, T. V.; Coropceanu, V.; Bredas, J. L.; Marder, S. R., J. Am. Chem. Soc. 2006, 128, 1812. (b) Low, P. J.; Paterson, M. A. J.; Puschmann, H.; Goeta, A. E.; Howard, J. A. K.; Lambert, C.; Cherryman, J. C.; Tackley, D. R.; Leeming, S.; Brown, B., Chem. Eur. J. 2004, 10,83 .

(13) (a) Noviandri, I.; Brown, K. N.; Fleming, D. S.; Gulyas, P. T.; Lay, P. A.; Masters, A. F.; Phillips, L., J. Phys. Chem. B 1999, 103, 6713. (b) Connelly, N. G.; Geiger, W. E., Chem. Rev. 1996, 96,877 .

(14) Sreenath, K.; Thomas, T. G.; Gopidas, K. R., Org. Lett. 2011, 13, 1134.

(15) Kaim, W.; Klein, A.; Glöckle, M., Acc. Chem. Res. 2000, 33, 755.

(16) (a) Richardson, D. E.; Taube, H., Coord. Chem. Rev. 1984, 60, 107. (b) Hildebrandt, A.; Lang, H., Organometallics 2013, 32, 5640. (c) Low, P. J.; Brown, N. J., J. Clust. Sci. 2010, 21, 235.

(17) (a) D'Alessandro, D. M.; Keene, F. R., Dalton Trans. 2004, 3950. (b) Winter, R. F., Organometallics 2014, 33, 4517. (c) Speck, J. M.; Claus, R.; Hildebrandt, A.; Rüffer, T.; Erasmus, E.; van As, L.; Swarts, J. C.; Lang, H., Organometallics 2012, 31, 6373.

(18) Barrière, F.; Geiger, W. E., J. Am. Chem. Soc. 2006, 128, 3980. 
(19) (a) Hankache, J.; Niemi, M.; Lemmetyinen, H.; Wenger, O. S., Inorg. Chem. 2012, 51, 6333. (b) Hankache, J.; Wenger, O. S., Chem. Commun. 2011, 47, 10145.

(20) (a) Lambert, C.; Nöll, G., J. Am. Chem. Soc. 1999, 121, 8434. (b) Lancaster, K.; Odom, S. A.; Jones, S. C.; Thayumanavan, S.; Marder, S. R.; Brédas, J. L.; Coropceanu, V.; Barlow, S., J. Am. Chem. Soc. 2009, 131, 1717.

(21) Brunschwig, B. S.; Creutz, C.; Sutin, N., Chem. Soc. Rev. 2002, 31, 168.

(22) Cave, R. J.; Newton, M. D., Chem. Phys. Lett. 1996, 249, 15.

(23) (a) Schmand, H. L. K.; Boldt, P., J. Am. Chem. Soc. 1975, 97, 447. (b) Menting, K. H.; Eichel, W.; Riemenschneider, K.; Schmand, H. L. K.; Boldt, P., J. Org. Chem. 1983, 48, 2814.

(24) Seo, E. T.; Nelson, R. F.; Fritsch, J. M.; Marcoux, L. S.; Leedy, D. W.; Adams, R. N., J. Am. Chem. Soc. 1966, 88, 3498.

(25) Lambert, C.; Nöll, G., Synth. Met. 2003, 139, 57.

(26) Jahnke, A. C.; Spulber, M.; Neuburger, M.; Palivan, C. G.; Wenger, O. S., Chem. Commun. 2014, 50, 10883.

(27) Lambert, C.; Nöll, G., Angew. Chem. Int. Ed. 1998, 37, 2107. 